\title{
Insights into crystallization and melting of high density polyethylene/graphene nanocomposites studied by fast scanning calorimetry
}

DOI:

10.1016/j.polymertesting.2018.03.029

\section{Document Version}

Accepted author manuscript

Link to publication record in Manchester Research Explorer

Citation for published version (APA):

Tarani, E., Papageorgiou, D. G., Valles, C., Wurm, A., Terzopoulou, Z., Bikiaris, D. N., Schick, C., Chrissafis, K., \& Vourlias, G. (2018). Insights into crystallization and melting of high density polyethylene/graphene nanocomposites studied by fast scanning calorimetry. Polymer Testing, 67, 349-358.

https://doi.org/10.1016/j.polymertesting.2018.03.029

\section{Published in:}

Polymer Testing

\section{Citing this paper}

Please note that where the full-text provided on Manchester Research Explorer is the Author Accepted Manuscript or Proof version this may differ from the final Published version. If citing, it is advised that you check and use the publisher's definitive version.

\section{General rights}

Copyright and moral rights for the publications made accessible in the Research Explorer are retained by the authors and/or other copyright owners and it is a condition of accessing publications that users recognise and abide by the legal requirements associated with these rights.

\section{Takedown policy}

If you believe that this document breaches copyright please refer to the University of Manchester's Takedown Procedures [http://man.ac.uk/04Y6Bo] or contact uml.scholarlycommunications@manchester.ac.uk providing relevant details, so we can investigate your claim.

\section{OPEN ACCESS}




\title{
Insights into crystallization and melting of high density \\ polyethylene/graphene nanocomposites studied by fast scanning calorimetry
}

\author{
E. Tarani ${ }^{1}$, D.G. Papageorgiou ${ }^{2}$, C. Valles $^{2}$, A. Wurm ${ }^{3}$, Z. Terzopoulou ${ }^{4}$, D.N. \\ Bikiaris $^{4}$, C. Schick ${ }^{3}$, K. Chrissafis ${ }^{1 *}$, G. Vourlias ${ }^{1}$ \\ ${ }^{1}$ Laboratory of X-ray, Optical Characterization and Thermal Analysis, Physics Department, \\ Aristotle University of Thessaloniki, GR-541 24 Thessaloniki, Greece \\ ${ }^{2}$ School of Materials and National Graphene Institute, The University of Manchester, Oxford \\ Road, Manchester M13 9PL, United Kingdom \\ ${ }^{3}$ University of Rostock, Institute of Physics, Albert Einstein Str. 23-24, 18059 Rostock, \\ Germany \\ ${ }^{4}$ Laboratory of Organic Chemical Technology, Department of Chemistry, Aristotle University \\ of Thessaloniki, GR-541 24 Thessaloniki, Greece
}

\begin{abstract}
Graphene nanoplatelets (5 wt.\%) with different diameters (5 and $25 \times 10^{-6} \mathrm{~m}$ in diameter, $6 \times 10^{-9} \mathrm{~m}$ in thickness) filled high density polyethylene nanocomposites were prepared by the melt-mixing method and the effect of graphene nanoplatelets on the polymeric matrix are then investigated by X-ray diffraction, polarized light microscopy, differential scanning calorimetry, fast scanning calorimetry, and rheology. Polarized light microscopy revealed that graphene nanoplatelets of $5 \times 10^{-6}$ $\mathrm{m}$ promote the decrease in the size of the spherical aggregates during crystallization compared to larger nanoplatelets. From rheological measurements, it was found that even though the viscosity of the nanocomposites with increasing filler diameter was increased significantly compared to the neat polymer, the processability of these
\end{abstract}


materials was not affected. Several melting events for neat high-density polyethylene and graphene nanocomposites were observed by fast scanning calorimetry associated with the small imperfect crystals grown at large supercooling, the nucleation efficiency and the diameter size of the filler. The activation energy values versus the relative extent of crystallization revealed that graphene nanoplatelets block the movement of the molecular segments and make crystallization difficult, especially at the final stage of the process. Based on this work, it can be concluded that the nanocomposite with the smaller diameter showed the most enhanced crystallization kinetics as graphene increased the number of nucleation sites, while the larger ones hindered the melted molecules in reaching full isotropization above the melting temperature.

Keywords: High Density Polyethylene; Graphene; Nanocomposites; Rheology; Fast Scanning Calorimetry; Activation Energy.

*corresponding author, address: Solid State Physics Section, Physics Department, Aristotle University of Thessaloniki, GR 54124 Thessaloniki, Greece, e-mail: hrisafis@physics.auth.gr, tel.: +30 2310998188. 


\section{Introduction}

There has been a growing interest in thermal conductive polymers (TCPs) such as thermal interface materials, electronics packaging and, plastic heat exchangers. TCPs are usually binary composites filled with high thermal conductivity additive in the matrix. The influence factors on the preparation of TCPs are filler size, functional treatment technique, volume fraction, directional alignment technique, and interfacial thermal resistance [1]. Among them, the filler size is one of the most important but easily overlooked factor.

Carbon-based nanomaterials such as graphene nanoplatelets (GNPs) have been proposed as the next generation multifunctional nanofiller for the improvement of matrices $[2,3]$. Graphene Nanoplatelets (GNPs) are ultrathin particles of graphite that can also be thought of as short stacks of graphene sheets. Graphene sheets are composed of $\mathrm{sp}^{2}$ hybridized carbon atoms linked in hexagonal structure with each carbon atom covalently bonded to three other carbon atoms [4]. So far, researchers have mainly focused on the effect of graphene content on the nucleation of thermally conductive high-density polyethylene (HDPE) nanocomposites at small supercooling [5], the functionalization and preparation methods of polyethylene, the improvement of thermal stability [6-12], and the study of mechanical properties of composites [13, 14]. However, there is limited literature available on the effect of graphene size on thermal properties of polyethylene [12, 15-17]. In our previous work [17], different size of GNPs was used to examine the non-isothermal crystallization kinetics of HDPE at cooling rates from 0.017 to $0.33 \mathrm{~K} / \mathrm{s}$. It was shown that GNPs with the smaller diameter increase more the number of heterogeneous crystallization nuclei. However, the above temperature range was very restricted due to limited cooling abilities of conventional Differential Scanning Calorimetry (DSC). 
Fast Scanning Calorimetry (FSC) offers perspectives for mimicking cooling and heating rates under practical conditions. Many industrial processes -film blow molding, injection molding, and extrusion- often occur under much higher cooling rates than the ones involved in common laboratory experiments, as for example in film production or microinjection molding cooling rates can be of the order of magnitude of $10.000 \mathrm{~K} / \mathrm{s}$ [18]. So, FSC analysis has been used to study the crystallization behavior and the melting kinetics of polymeric crystals formed far from thermodynamic equilibrium, which readily undergo the reorganization of themselves during the examination by fast scanning rates [19-23]. FSC have been applied to examine polyethylene [24-26] at high scanning rates using sample masses in the range of $1-30 \times 10^{-11} \mathrm{Kg}$ without significant temperature lag [20, 21]. A supercooling of the melt by $40 \mathrm{~K}$ was observed for a linear polyethylene sample $(1.2 \mathrm{x}$ $10^{-10} \mathrm{Kg}$ ) expanded to $5000 \mathrm{~K} / \mathrm{s}$ [19]. Recently, Zhuravlev et al. [18] examined the supercooling of polyethylene of various chemical architecture down to $330 \mathrm{~K}$ using a mass of $1-2 \times 10^{-12} \mathrm{Kg}$ at rates up to $1000000 \mathrm{~K} / \mathrm{s}$. However, the crystallization mechanism of HDPE/graphene nanocomposites in a wide range of technological processes (relevant to polymer manufacturing processes) and the reorganization processes of HDPE crystals that occurred far from thermodynamic equilibrium have not yet extensively been studied.

In this work, crystallization and melting behavior of HDPE/graphene nanocomposites with different diameters (5 and $25 \times 10^{-6} \mathrm{~m}$ ) were studied in non-isothermal conditions over a broad temperature range regarding the use of FSC to better understand the effect of graphene size on the crystallization far from thermodynamic equilibrium. Conventional techniques such as Polarized Light Microscopy (PLM) and DSC were also applied to observe the nucleating effect of GNPs on the polymeric 
matrix at small supercooling. A comprehensive analysis of graphene size in the storage/loss modulus and viscosity in the nanocomposites was explored. An isoconversional technique was examined to evaluate the apparent activation energy of the nanocomposites during the crystallization process. These results can be employed to describe the overall crystallization kinetics of thermally conductive HDPE/graphene nanocomposites in polymer processing.

\section{Experimental Section}

\subsection{Materials}

High density polyethylene (HDPE) under the trade name Lumicene ${ }^{\circledR}$ mPE M5510 EP was supplied by Total Petrochemicals (Feluy, Belgium). Lumicene ${ }^{\circledR}$ mPE M5510 EP is a linear backbone of the repeating unit $-\left(\mathrm{CH}_{2}-\mathrm{CH}_{2}\right)_{n}-$ with a slight degree of branching prepared with metallocene catalyst. It has a melt flow index of $1.2 \mathrm{~g} / 10 \mathrm{~min}$ (ISO 1133 ) and $955 \mathrm{Kg} / \mathrm{m}^{3}$ density. GNPs with an average thickness of $6 \times 10^{-9} \mathrm{~m}$ were supplied by XG Sciences Inc., USA having two different average diameters: GNPs with an average platelet diameter of $5 \times 10^{-6} \mathrm{~m}$ (GNP M5) and $25 \times 10^{-6} \mathrm{~m}$ (GNP M25), respectively. The average surface area ranges from 120 to $150 \mathrm{~m}^{2} / \mathrm{g}$. The bulk density of all GNPs is reported to be $2200 \mathrm{Kg} / \mathrm{m}^{3}$.

\subsection{Nanocomposites preparation}

HDPE/graphene nanocomposites containing $5 \mathrm{wt} \%$ of GNPs were prepared by meltmixing in a Haake-Buchler Reomixer (model 600) equipped with roller blades and a mixing head with a volumetric capacity of $6.9 \times 10^{-5} \mathrm{~m}^{3}$. During the mixing period, the melt temperature and torque were continuously recorded. For this set of samples, a mixing was performed at $473 \mathrm{~K}$, for $300 \mathrm{~s}$, using a torque speed of $35 \mathrm{rpm}$. 
Afterwards the prepared materials were hot pressed using an Otto Weber, Type PW 30 hydraulic press connected with an Omron E5AX Temperature Controller, at a temperature of $453 \pm 5 \mathrm{~K}$ in order to prepare films of different thicknesses, therefore appropriate for each type of following measurements. The nanocomposite samples are referred here as HDPE/M5 and HDPE/M25.

\subsection{Characterization Method}

\subsubsection{Differential Scanning Calorimetry (DSC)}

A differential scanning calorimeter (DSC) Pyris Diamond from Perkin-Elmer, calibrated with indium and zinc standards, was used for the calorimetric behavior of HDPE and the graphene nanocomposites. The selected sample mass was $1.75 \pm 0.1$ $\mathrm{x} 10^{-6} \mathrm{Kg}$ to minimize heat flow to the sample which is proportional to rate and sample mass and causes the thermal lag. As to the non-isothermal crystallization kinetics, the thermal history of all samples was erased by heating from room temperature up to 453 $\mathrm{K}$ and then the samples were held at this temperature for $120 \mathrm{~s}$. Then, cooling scans were performed at rates of $0.17,0.33,0.83,1.67$ and $2.5 \mathrm{~K} / \mathrm{s}$. Subsequent melting after non-isothermal crystallization was measured at a heating rate of $0.33 \mathrm{~K} / \mathrm{s}$. The crystallinity of the samples is determined from the ratio of the measured area under the curve concerning the area under $100 \%$ crystalline HDPE material (293 J/g [27]) normalized by the mass fraction of HDPE in the composites.

\subsubsection{Fast Scanning Calorimetry (FSC)}

The non-isothermal crystallization behavior of HDPE/graphene nanocomposites was explored by FSC to study the effect of supercooling on the crystallization process. A detailed description of the measurement principle and instrumental setup, Mettler- 
Toledo Flash DSC 1, is given elsewhere [19,28]. During the experimental procedure, the sample was microtomed under a microscope and placed in the center of the sensor, namely UFS1 MultiSTAR chip sensor. It was then melted at a low heating rate of $10 \mathrm{~K} / \mathrm{s}$ to establish good thermal contact between the sample and the sensor. The samples were then heated from room temperature to $473 \mathrm{~K}$ and held there for $0.1 \mathrm{~s}$ to erase the thermal history, and then cooled down to $223 \mathrm{~K}$ at different cooling rates, ranging from 1 to $10000 \mathrm{~K} / \mathrm{s}$ (starting with the faster cooling rate) under a constant flow $\left(5 \times 10^{-7} \mathrm{~m}^{3} / \mathrm{s}\right)$ of dry nitrogen gas over the chip sensor. The sample mass was roughly estimated $(170 \pm 10 \mathrm{ng})$ by comparing the absolute enthalpies of crystallization, measured by FSC, with mass-specific enthalpies of crystallization, obtained by conventional DSC at the same condition of crystallization.

\subsubsection{Rheological measurements}

A TA rheometer with parallel plate geometry $(0.0007 \mathrm{~m}$ gap and $0.025 \mathrm{~m}$ diameter $)$ was used at a temperature of $453 \mathrm{~K}$ to analyze the dynamic and steady shear properties of polymer and composites. Dynamic frequency sweeps were conducted within the linear viscoelastic region at a constant strain of $1 \%$, and the variation of $G^{\prime}$ and $G^{\prime \prime}$ with increasing frequency (from 0.1 to $628 \mathrm{rad} / \mathrm{s}$ ) has been studied. Steady shear sweeps were used to investigate the flow properties of the materials by recording the viscosity at increasing shear rates (from 0.001 to $300 \mathrm{~s}^{-1}$ ).

\subsubsection{Polarized light microscopy (PLM)}

A polarizing light microscope (Nikon, Optiphot-2) equipped with a Linkam THMS 600 heating stage, a Linkam TP 91 control unit, and a Jenoptic ProgRes C10Plus camera was used for PLM observations. The sample on glass slides covered with slips 
heated to $443 \mathrm{~K}$, held for $60 \mathrm{~s}$ at this temperature and then cooled to room temperature at a cooling rate of $0.33 \mathrm{~K} / \mathrm{s}$.

\subsubsection{X-ray Diffraction (XRD)}

The XRD patterns of the prepared materials $(0.03 \mathrm{~m}$ in thickness $)$ were recorded at Bragg-Brentano geometry using a two-cycles Rigaku Ultima + powder X-ray diffractometer (Rigaku Corporation, Shibuya-Ku, Tokyo, Japan) with CuKa radiation, using a step size of $0.05^{\circ}$ and a step time of $2 \mathrm{~s}$ operating at $40000 \mathrm{~V}$ and $0.03 \mathrm{~A}$.

\section{Results and discussion}

\subsection{Study of crystallites and crystal structure of HDPE/graphene nanocomposites}

PLM study of HDPE/graphene nanocomposites was carried out at a cooling rate of $0.33 \mathrm{~K} / \mathrm{s}$. It is well known that polyethylene crystallites are arranged in spherical aggregates, and thus it is difficult to observe spherulitic morphology [29]. Fig. 1.a. shows that the size of spherical aggregates decreases in the case of HDPE/M5 nanocomposite compared to HDPE/M25 nanocomposite (Fig. 1.b). This can be judged by the number of light spots in the field of view. Similar morphology behavior has been observed in other HDPE composites [30, 31]. The larger number of aggregates might originate from GNPs M5 into the HDPE matrix, indicating that the heterogeneous nucleating effect is stronger as the filler diameter decreases (at the same filler content) due to the higher number of nucleating sites. Moreover, Fig. 1 shows that large black GNP aggregates are dispersed coarsely in HDPE/M5 and HDPE/M25 nanocomposites. The black aggregates become smaller in the case HDPE/M5 nanocomposite compared to HDPE/M25 filled with GNPs M25. This probably means that the dispersion of GNPs M5 is finer in HDPE matrix than GNPs 
M25. GNPs M25 may present agglomerations which probably reduce its nucleation activity and support the development of larger aggregates. Similar results have been reported in the literature [31].

X-ray diffraction patterns of neat HDPE, HDPE/M5 and HDPE/M25 nanocomposites, are shown in Fig. 2. Neat HDPE and graphene nanocomposites are characterized by four strong peaks, reflections (llll 110$),\left(\begin{array}{lll}2 & 0 & 0\end{array}\right),\left(\begin{array}{lll}2 & 10\end{array}\right)$ and $\left(\begin{array}{lll}0 & 2 & 0\end{array}\right)$, corresponding to the orthorhombic phase (Pnam space group) of polyethylene [32]. These peaks are individually located at $2 \theta$ values of $21.6^{\circ}, 24^{\circ}, 30.2^{\circ}$ and $36.4^{\circ}$, respectively. Both HDPE/M5 and HDPE/M25 nanocomposites exhibit a sharp diffraction peak at $2 \theta \approx$ $26.5^{\circ}$, which represents the diffraction of the (002) crystal plane of GNPs [33]. The normalized intensity of (002) crystal plane in the HDPE/M25 sample is slightly higher than that in the HDPE/M5 nanocomposite even though the two nanocomposites have the completely same GNP content. It is suggested that the relatively high intensity of GNPs M25 in HDPE/M25 nanocomposite is possibly related to filler diameter; GNPs M25 may be aggregated together as shown in Fig. 1.b.

\subsection{Rheological properties of HDPE/graphene nanocomposites}

The rheological properties of the HDPE, HDPE/M5 and HDPE/M25 nanocomposites (including dynamic shear and steady shear properties) are comparatively shown in Fig. 3. Fig. 3.a. shows the variation of $G^{\prime}$ (storage modulus) and $G^{\prime \prime}$ (loss modulus) with increasing frequency. HDPE and the graphene nanocomposites exhibit the classical polymer melt behavior with $G^{\prime}$ and $G^{\prime \prime}$ decreasing with decreasing frequency and a clear terminal zone in the low-frequency range. The $G^{\prime \prime}$ of samples are distinctively higher than their corresponding $G^{\prime}$ and show a monotonic increase over this frequency range. Nevertheless, at the high-frequency region $(\sim 158 \mathrm{rad} / \mathrm{s})$, the $G^{\prime}$ 
and $G^{\prime \prime}$ of all materials coincide and appear to cross over. This cross over suggests the transition from viscous to elastic behavior. Compared to the HDPE/M5 nanocomposite, the increase in both $G^{\prime}$ and $G^{\prime \prime}$ of HDPE/M25 is more pronounced, indicating that the large-scale relaxation of HDPE chains is more restrained by the presence of the larger GNPs compared to the smaller ones. Higher values for the moduli are observed for the composites relative to the neat polymer, which evidences the formation of a graphene network in the matrix. Higher values of these moduli were found for bigger nanoplatelets relative to the smaller ones, which suggests that the formation of a 3D network of graphene is easier for graphene nanoplatelets with bigger lateral dimensions at the same loading. This dependence on aspect ratio has been shown previously through the comparison of the rheological behavior of high aspect ratio graphite nanoplatelets and short graphene oxide in PEN [34, 35].

Fig. 3.b. shows the mechanical loss factor $(\tan \delta)$ of HDPE/graphene nanocomposites with different filler size. The $\tan \delta$ is related significantly to the applied angular frequency. When scanning the experimental frequencies from low to high, the $\tan \delta$ of nanocomposites decreases with increasing filler size. The higher $\tan \delta$ of neat HDPE compared to the nanocomposites is due to the free relaxation of the HDPE chains, while the polymer chain relaxation and the relative motion have significantly been restrained adding GNPs [36].

In addition, Fig. 3.c. shows the viscosity profiles (steady shear properties), $(\eta)$, in the frequency range of 0.001-300 $\mathrm{s}^{-1}$. The viscosity of all studied materials changes from a Newtonian plateau at low frequencies to a continuous decrease with increasing shear rates, which we attribute to the breakage of the graphene interconnected network formed in the matrix (at rest and low frequency shear there is a network of graphene formed in the matrix, which breaks at higher frequencies, and that is why we see that 
decrease in viscosity, the shear-thinning behaviour). At high frequency regions both HDPE/M5 and HDPE/M25 nanocomposites exhibit shear-thinning behavior. This attributes to the alignment of GNPs in the direction of shear, where the filler content has a small effect on the viscosity of composites and the relaxation mechanism is mainly governed by the polymer matrix [37]. Similar to moduli, the viscosity of the graphene nanocomposites is much higher than the neat HDPE at all range. Specifically, there is an increase in zero-shear viscosity by $524 \%$ and $679 \%$ for HDPE/M5 and HDPE/M25, respectively. This remarkable enhancement in zero-shear viscosity may be due to agglomeration of GNPs resulting in significant interaction between anisotropic graphene platelets (and the formation of a graphene interconnected network), which initiate a strong dependence of viscosity on graphene size. Consequently, the HDPE/M25 nanocomposite exhibits apparently enhanced $G^{\prime}$, $G^{\prime \prime}$ (related to reinforcement of the matrix) and increased $\eta$ compared to HDPE/M5 and neat HDPE. This means that the bulk density of GNPs in the HDPE/M25 nanocomposite is much higher than that of the HDPE/M5 nanocomposite despite the same filler content (5 wt \% of GNPs) and thus GNPs M25 greatly restrict the mobility of the molecular chains [38]. The increase in viscosities observed was not too high, and it was still possible to process the materials easily, even at loadings of $5 \mathrm{wt} \%$, which represents an important advantage for using these nanocomposites in industry.

\subsection{Crystallization behavior of HDPE/graphene nanocomposites}

The high nucleation density of the nanocomposites plays a major role on the crystallization rates of the samples; there is a high number of nucleating sites which accelerate the general crystallization phenomenon. So, the crystallization behavior of HDPE/M5 and HDPE/M25 nanocomposites was investigated by conventional DSC 
using cooling rates ranging from 0.17 to $2.5 \mathrm{~K} / \mathrm{s}$. The selected DSC curves of neat HDPE and HDPE/M5 nanocomposite are plotted as a function of the temperature in Fig. 4. Higher cooling rates favor crystallization at a lower temperature resulting in less perfect crystallites of small dimensions. FSC was also performed to extend the available scanning-rate range and time resolution of conventional DSCs far from thermodynamic equilibrium. The selected curves of HDPE/M5 nanocomposite cooled at rates between 1 and $10000 \mathrm{~K} / \mathrm{s}$ (starting the measurements with the faster cooling rate), are plotted as a function of the temperature in Fig. 5. Even at the highest cooling rate, a broad crystallization peak is observed revealing that a fully amorphous glassy state could not be reached at these rates.

Peak temperatures of neat HDPE, HDPE/M5 and HDPE/M25 nanocomposites (Fig. 6.a) shift towards higher values with decreasing cooling rate. In comparison with FSC, results of crystallization obtained by conventional DSC are added (solid symbols) in Fig. 6.a. The crystallization process is much faster in the case of FSC than standard DSC due to the different cooling conditions applied in both instruments. The decrease in crystallization peak temperatures, as caused by decreasing the cooling rate from 10000 to $1 \mathrm{~K} / \mathrm{s}$, amount to approximately $81 \mathrm{~K}, 66 \mathrm{~K}$ and $64 \mathrm{~K}$ for neat HDPE, HDPE/M5 and HDPE/M25, respectively. This reveals that the undercooling of HDPE/M5 and HDPE/M25 nanocomposites is smaller than that of neat HDPE. Consequently, there is a high number of nucleating sites in nanocomposites promoting crystallization even at such high cooling rates. Fig. 6.b. shows that the crystallization enthalpy of the HDPE, HDPE/M5, and HDPE/M25 nanocomposites increases slightly up to a cooling rate of $100 \mathrm{~K} / \mathrm{s}$, while it significantly increases after that. These findings suggest that the crystallinity of the samples may be controlled by the thermal cycles of cooling and heating to which the material is subjected. In particular, the 
cooling rates are fast enough, and thus, there is no time to form crystals with high perfection; disordered regions and crystallites of varying sizes crystals are formed at low temperatures [39]. An increasing cooling rate leads to a high supercooling, while the thermodynamic driving power of crystallization also increases. By increasing the viscosity, caused by the cooling of the melt, however, the mobility of the molecule chains slows down. It seems that the thermodynamic and kinetic requirements for crystallization work against each other, and thus, there is only a slight increase in crystallization enthalpy of neat HDPE, i.e., from $138.95 \mathrm{~J} / \mathrm{g}$ to $143.43 \mathrm{~J} / \mathrm{g}$ decreasing the cooling rate from 1000 to $100 \mathrm{~K} / \mathrm{s}$. With decreasing the cooling rate further (from 100 to $1 \mathrm{~K} / \mathrm{s}$ ), the amount of the ordered structures and the stability of crystals formed in the cooling process increases (as is judged by the shift of the crystallization peak toward higher values in Fig. 6.a.), and therefore, the crystallization enthalpy and the crystallinity increase more. It is furthermore observed that the crystallization enthalpy, as well as the crystallinity of nanocomposites have both decreased compared to neat HDPE (Fig. 6.b). On the one hand, graphene nanoplatelets provide a higher number of available nucleating sites due to the increase in surface area to volume ratio for decreasing particle size. On the other hand, a reduction in mobility of the molecular chains can occur under the presence of the filler which reduces crystal growth rate and filler effectiveness. Similar results have been presented in the literature [40, 41].

\subsection{Melting behavior following the non-isothermal crystallization of HDPE and the graphene nanocomposites}

Conventional DSC heating curves of neat HDPE and HDPE/M5 nanocomposite at a rate of $0.33 \mathrm{~K} / \mathrm{s}$ after cooling at various rates from 0.17 to $2.5 \mathrm{~K} / \mathrm{s}$ are shown in Fig. 7 . These cooling rates are slow enough, and as a result, more stable and larger crystals 
are formed. The incorporation of GNPs into the HDPE matrix increases the melting temperature. The smaller GNPs M5 shift the melting peak of HDPE to higher temperatures than the larger ones (GNPs M25). In addition, the melting enthalpy, and therefore the crystallinity (Table 1) decrease with increasing cooling rate. GNPs provide higher interfacial area and interaction between the polymer matrix which can lead to a retardation of the molecular mobility [12, 42]. Meanwhile, the melting enthalpy of HDPE/M5 nanocomposite presents slightly higher values than HDPE/M25. The same behavior was also observed at crystallization temperatures of these samples (Fig. 6.b).

Graphene nanocomposites were studied by FSC at a heating rate of $1000 \mathrm{~K} / \mathrm{s}$ to separate the different melting events (Fig. 8). The observed changes in melting were attributed to the cooling procedure, since the heating conditions were kept the same for all samples (heating at $1000 \mathrm{~K} / \mathrm{s}$ ). Several melting events for neat HDPE and the graphene nanocomposites were observed, since the melting peaks were broad and overlapping. Multiple endotherm phenomena for HDPE under various crystallization conditions have been observed in the literature [43-45]. In particular, G. Amarasinghe et al. [44] reported that the process of melting, recrystallization, and remelting occurs in HDPE sample; A. Toda et al. [25] reported that the crystals formed at low temperatures are unstable and easily re-organize during heating. It means that the crystals of semi-crystalline polymer contain disordered regions and crystallites of varying sizes due to ethylene sequence length distribution, crystallizing at different temperatures [46-48]; these disordered regions and crystallites of varying size behave differently when both the cooling rate and filler size increase and thus various melting events exist in the heating curves, as shown in Fig. 8. 
To quantify the influence of the GNPs on HDPE crystallization, a curve deconvolution was performed in order to evaluate the peak temperature of each disordering event (melting of crystals) and its dependence on crystallization conditions. The peak position in the overlapped thermograms was adjusted by a nonlinear least-squares method so that the summed profile was fitted to the observed pattern using Lorentzian and Gaussian functions (Fig. 8.d.) [49].

HDPE is a very fast crystallizing and recrystallizing polymer and thus rates as high as $1000 \mathrm{~K} / \mathrm{s}$ cannot prevent reorganization (Fig. 8.a.). The multiple melting peaks are related to a series of crystals with different crystallites sizes. So, the sharp melting peaks observed after the application of slow cooling rates are attributed to the melting of crystals with higher perfection, compared to the ones that are formed at larger undercooling at the rate of $10.000 \mathrm{~K} / \mathrm{s}$. The nanocomposites filled with GNPs show faster overall crystallization because of the filler nucleation activity. However, fast crystallization always results in the formation of less stable structures (poor crystals). According to the literature [50,51], neat HDPE is composed of long chains which form irregular, entangled coils in the melt. In HDPE/graphene nanocomposites, polymer chains repel nanofillers (when GNPs are added in the polymer matrix, the HDPE chains are stretched, a fact that decreases the conformational entropy of chains), and thus the distance between entanglements change throughout the polymer matrix in the melt [52]. However, GNPs M25 with the larger diameter can form aggregates more easily into the polymer matrix than GNPs M5 at the same loading 5 wt.\%, as shown in PLM and rheological measurements. In this case, it is difficult for a polymer chain to wrap around the GNP M25; the interfacial area diminishes and does not contribute to the net packing fraction. It has been shown that the excluded volume of the nanoscale fillers coupled with the configurational entropy of the polymer chain 
plays an important role in the spatial distribution of nanofillers in polymer matrices [52]. In other words, when the diameter of filler increases, it is difficult the filler to disperse isotropically into the polymer matrix. Therefore, various ordering events are shown in the overlapped DSC melting curves of HDPE/M25 nanocomposite (Fig. 8.d) attributed to the small imperfect crystals grown at large supercooling, the nucleation activity of the filler and the large diameter of GNPs M25.

Fig.9. a. shows the above-described different ordering events as a function of the cooling rate in logarithmic scale. The melting temperature is strongly affected by the filler size as the peaks of nanocomposites can be observed at a higher temperature than neat HDPE at the same rate. However, the melting peaks IV of the HDPE/M5 nanocomposite appear at lower temperatures indicating the presence of many small and imperfect crystals, which do not organize in a high-order superstructure at this large supercooling $[53,54]$. The melting point of HDPE/M25 nanocomposite is further increased because GNPs M25 with the larger diameter hinder the melted molecules to reach full isotropization above the melting temperature. It has been reported that melting into a strained rather than an isotropic melt results in more perfect crystals and an increase of the observed melting temperature [55].

The total melting enthalpy of neat HDPE, HDPE/M5 and HDPE/M25 nanocomposites (Fig. 9.b) depends strongly on cooling rate. At slow cooling (1 K/s), a very large crystallization peak is observed, which gradually decreases with increasing cooling rate. These observations agree with the analysis of samples crystallized during conventional DSC measurements.

\subsection{Non-isothermal crystallization kinetics of HDPE and the graphene} nanocomposites 
In order to shed light on the kinetics of graphene nanocomposites at various temperatures, the relative degree of crystallinity $\left(X_{T}\right)$ is obtained by dividing the heat that develops at each crystallization temperature $\left(\Delta H_{T}\right)$ over the whole area under the exothermic peak, that is, the total heat $\left(\Delta H_{0}\right)$ generated up to the complete crystallization [56]. Fig. 10 shows the relative crystallinity of neat HDPE as a function of time at cooling rates ranging from 0.17 to $10000 \mathrm{~K} / \mathrm{s}$ collected by FSC (line) and conventional DSC (dot line). The crystallization of the samples at faster cooling rates occurs at lower temperatures because there is no time to organize the chain configurations into perfect crystallites, and as a result, the extent of crystallite perfection decreases with faster cooling rates. The relative extent of crystallization, obtained for each cooling rate from FSC and conventional DSC, does not overlap with each other, which is an essential prerequisite for accurate isoconversional kinetic computations.

The half time of non-isothermal crystallization $\left(t_{1 / 2}\right)$ of neat HDPE, HDPE/M5 and HDPE/M25 nanocomposites, defined as the time taken to reach the relative crystallinity at a value of $50 \%$, can be obtained from the $X_{t}$ versus time curve (Fig. 11). At increasing supercooling, the $t_{1 / 2}$ values decrease because of the increase in the thermodynamic driving force of crystallization. At a given cooling rate, the $t_{1 / 2}$ values of graphene nanocomposites do not present any differences for different filler size. However, the values of nanocomposites are increased more than neat HDPE, especially at low cooling rates. This indicates that the addition of GNPs in HDPE decelerates the overall crystallization process of matrix. GNPs behave as a barrier during the mass transfer forming a tortuosity in the diffusion path, which decreases the free volume and retard the crystalline-amorphous interface movement $[12,42]$. 
The differential iso-conversional method of Friedman [57] has been used for HDPE and the graphene nanocomposites to obtain reliable values of the apparent activation energy over a broad temperature range. By plotting $\ln (d X t / d t)$ as a function of $1 / T_{X_{t}}$ for each conversion and different cooling rates, the crystallization activation energy can be calculated from the slope. The dependence of the apparent activation energy on relative crystallinity for neat HDPE, HDPE/M5 and HDPE/M25 nanocomposites, determined by DSC (filled symbols) and FSC (open symbols), is shown in Fig. 12.a. Since energy has been released crystallizing from the molten fluid to the ordered crystalline state, the value of activation energy will be negative. The values of the apparent activation energy of neat HDPE, HDPE/M5 and HDPE/M25 increase with the degree of crystallinity for both conventional and fast DSC. This suggests that it is more difficult for each polymer system to crystallize, as the crystallization proceeds. The determined values of FSC are higher than those of standard DSC (Fig. 12.b) in agreement with the assumption of Bosq et al. [58] that the crystallization temperature ranges are very different leading to different $E_{X_{t}}$ temperature dependencies. These data, derived from both instruments, give an opportunity to compute activation energy values on an extensive temperature range.

The values of activation energy for HDPE/M5 and HDPE/M25 nanocomposites are higher than neat HDPE, but the HDPE/M5 sample presents slightly lower values and crystallizes at more elevated temperature than HDPE/M25. As already mentioned above at PLM, DSC and FSC techniques, GNPs M5 have higher nucleation efficiency at these rates resulting in a more significant number of nuclei. Considering all the above results, faster crystallization proceeds at the beginning of the process because GNPs increase the number of nucleation sites and thereby decrease the average size of crystallites. However, GNPs can readily adsorb the polyethylene molecular segments 
and then they block the movement of molecular segments and make crystallization difficult.

When the diameter increases, the bulk density of the filler will also increase significantly, and as a result, the tensile strength of the aggregates increases strongly. The observed slower crystallization in the case of HDPE/M25 nanocomposite, due to the decreased spherulitic growth rates and lower nucleation density, results in the melt viscosity increase as shown in Fig. 3. This affects the translational/rotational restrictions along the chain backbone and thus should lead to higher values of the activation energy at these harsh melt conditions.

\section{Conclusions}

The crystallization behavior of thermally conductive HDPE/graphene nanocomposites filled with nanoplatelets of different size ( 5 and $25 \times 10^{-6} \mathrm{~m}$ in diameter) was studied using fast scanning calorimetry. The high cooling rates yield structure formation far from thermodynamic equilibrium. The melting behavior of neat HDPE, HDPE/M5, and HDPE/M25 after cooling at 1-10000 K/s, in which various melting events take place, was discussed for the first time. These melting events were associated with the formation of small ordered domains which do not form a high-order superstructure at these rates, as well as the large nucleation density of GNPs. Moreover, this study provides an advanced isoconversional analysis of HDPE/graphene nanocomposites crystallization kinetics over a broad temperature domain using conventional and fast calorimetric data. The apparent activation energy of the nanocomposites was calculated according to Friedman's theory, and the fact that the nanocomposites presented higher values than the HDPE matrix is once more an indication that graphene nanoplatelets hinder the movement of the molecular segments and make 
crystallization difficult, especially at the final stage of the process. The melt shear viscosity of HDPE/M5 and HDPE/M25 nanocomposites suggested the strong orientation of filler layers in the flow direction at low shear rates, as well as the shearthinning behavior of samples at higher shear rates indicating the dominance of shear rheological properties of the neat polymeric system. The processability of HDPE/M5 and HDPE/M25 nanocomposites was not affected as similar processing conditions to the neat polymer were still suitable for the processing of the nanocomposites. In conclusion, HDPE/M25 nanocomposite showed slower crystallization and increased rheological properties because of the denser packing followed by the formation of crystals with larger spherical aggregates, resulting in less influence on the mechanical properties of materials, which will be discussed in future work.

\section{References}

[1] H. Wang, J. Gong, Y. Pei, Z. Xu, Thermal transfer in graphene-interfaced materials: Contact resistance and interface engineering, ACS Appl. Mater. Interfaces. 5 (2013) 2599-2603. doi:10.1021/am3032772.

[2] D.G. Papageorgiou, I.A Kinloch, R.J. Young, Mechanical properties of graphenebased nanocomposites, Prog. Mater. Sci. $90 \quad$ (2017) 75-127. doi:10.1016/j.pmatsci.2017.07.004.

[3] R.J. Young, M. Liu, I.A. Kinloch, S. Li, X. Zhao, C. Valles, D.G. Papageorgiou, The mechanics of reinforcement of polymers by graphene nanoplatelets, Compos. Sci. Technol. 154 (2018) 110-116. doi:10.1016/j.compscitech.2017.11.007.

[4] M.J. Allen, V.C. Tung, R.B. Kaner, Honeycomb carbon: a review of graphene, Chem. Rev. 110 (2010) 132-145. doi:10.1021/cr900070d. 
[5] F. Shehzad, S.P. Thomas, M.A. Al-Harthi, Non-isothermal crystallization kinetics of high density polyethylene/graphene nanocomposites prepared by in-situ polymerization, Thermochim. Acta. $589 \quad$ (2014) 226-234. doi:10.1016/j.tca.2014.05.039.

[6] H. Kim, S. Kobayashi, M.A. AbdurRahim, M.J. Zhang, A. Khusainova, M.A. Hillmyer, A.A. Abdala, C.W. Macosko, Graphene/polyethylene nanocomposites: Effect of polyethylene functionalization and blending methods, Polymer (Guilf). 52 (2011) 1837-1846. doi:10.1016/j.polymer.2011.02.017.

[7] M.E. Achaby, A. Qaiss, Processing and properties of polyethylene reinforced by graphene nanosheets and carbon nanotubes, Mater. Design. 44 (2013) 81-89. doi:10.1016/j.matdes.2012.07.065.

[8] F. Fim, N.R.S. Basso, A.P. Graebin, D.S. Azambuja, G.B. Galland, Thermal, electrical, and mechanical properties of polyethylene-graphene nanocomposites obtained by in situ polymerization, J. Appl. Polym Sci. 128 (2013) 2630-2637. doi:10.1002/app.38317.

[9] F. Shehzad F, M. Daud, M.A. Harthi, Synthesis, characterization and crystallization kinetics of nanocomposites prepared by in situ polymerization of ethylene and graphene, J. Therm. Anal. Calorim. 123 (2016) 1501-1511. doi: 10.1007/s10973-015-5087-x.

[10] V. Mittal, S. Kim, S. Neuhofer, C. Paulik, Polyethylene/graphene nanocomposites: effect of molecular weight on mechanical, thermal, rheological and morphological properties, Colloid Polym. Sci. 294 (2016) 691-704. doi: 10.1007/s00396-015-3827-x.

[11] V. Mittal, A.U. Chaudhry, Polyethylene-thermally reduced graphene nanocomposites: comparison of masterbatch and direct melt mixing approaches on 
mechanical, thermal, rheological, and morphological properties, Colloid Polym. Sci. 294 (2016) 1659-1670. doi: 10.1007/s00396-016-3929-0.

[12] E. Tarani, Z. Terzopoulou, D.N. Bikiaris, T. Kyratsi, K. Chrissafis, G. Vourlias, Thermal conductivity and degradation behavior of HDPE/graphene nanocomposites: Pyrolysis, kinetics and mechanism, J. Therm. Anal. Calorim. 129 (2017) 1715-1726. doi:10.1007/s10973-017-6342-0.

[13] A.J. Bourque, R.C. Locker, A.H. Tsou, M. Vadlamudi, Nucleation and mechanical enhancements in polyethylene-graphene nanoplate composites, Polymer. 99 (2016) 263-272. doi:10.1016/j.polymer.2016.07.025.

[14] S. Park, S. He, J. Wang, A. Stein, C.W. Macosko, Graphene-Polyethylene Nanocomposites: Effect of Graphene Functionalization, Polymer. 104 (2016) 1-9. doi:10.1016/j.polymer.2016.09.058.

[15] P.N. Khanam, M.A. AlMaadeed, M. Quederni, B. Mayoral, A. Hamilton A, D. Sun, Effect of two types of graphene nanoplatelets on the physico-mechanical properties of linear low-density polyethylene composites, Adv. Manuf. Polym. Comps. Sci. 2 (2016) 67-73. doi:10.1080/20550340.2016.1235768.

[16] Z. Jing, C. Li, H. Zhao, G. Zhang, B. Han, Doping effect of graphene nanoplatelets on electrical insulation properties of polyethylene: from macroscopic to molecular scale, Materials 9 (2016) 680-692. doi:10.3390/ma9080680.

[17] E. Tarani, A. Wurm, C. Schick, D.N. Bikiaris, K. Chrissafis, G. Vourlias, Effect of graphene nanoplatelets diameter on non-isothermal crystallization kinetics and melting behavior of high density polyethylene nanocomposites, Thermochim. Acta. 643 (2016) 94-103. doi:10.1016/j.tca.2016.09.018. 
[18] E. Zhuravlev, V. Madhavi, A. Lustiger, R. Androsch, C. Schick, Crystallization of polyethylene at large undercooling, ACS Macro Lett. 5 (2016) 365-370. doi:10.1021/acsmacrolett.5b00889.

[19] V. Mathot, M. Pyda, T. Pijpers, G.V. Poel, E. Kerkhof, S. Herwaarden, F. Herwaarden, A. Leenaers, The Flash DSC 1, a power compensation twin-type, chipbased fast scanning calorimeter (FSC): First findings on polymers, Thermochim. Acta. 522 (2011) 36-45. doi:10.1016/j.tca.2011.02.031.

[20] S.A. Adamovsky, A. Minakov, C. Schick, Scanning microcalorimetry at high cooling rate, Thermochim. Acta. 403 (2003) 55-63. doi:10.1016/S00406031(03)00182-5.

[21] X. Tardif, B. Pignon, N. Boyard, J.W.P. Schmelzer, V. Sobotka, D. Delaunary, C. Schick, Experimental study of crystallization of polyetheretherketone (PEEK) over a large temperature range using a nano-calorimeter, Polym. Test. 36 (2014) 10-19. doi:10.1016/j.polymertesting.2014.03.013.

[22] D.G. Papageorgiou, E. Zhuravlev, G.Z. Papageorgiou, D. Bikiaris, K. Chrissafis, C. Schick, Kinetics of nucleation and crystallization in poly(butylene succinate) nanocomposites, Polymer. 55 (2014) 6725-6734. doi:10.1016/j.polymer.2014.11.014. [23] D.G. Papageorgiou, G.Z. Papageorgiou, E. Zhuravlev, D. Bikiaris, C. Schick, K. Chrissafis, Competitive crystallization of a propylene/ethylene random copolymer filled with a $\beta$-nucleating agent and multi-walled carbon nanotubes. Conventional and ultrafast DSC study, J. Phys. Chem. B 117 (2013) 148745-14884. doi: 10.1021/jp409395h.

[24] A.A. Minakov, C. Schick, Ultrafast thermal processing and nanocalorimetry at heating and cooling rates up to $1 \mathrm{MK} / \mathrm{s}$. Rev. Sci. Instrum. 78 (2007) 073902-073910. doi:10.1063/1.2751411. 
[25] A. Toda, K. Taguchi, K. Nozaki, M. Konishi, Melting behaviors of polyethylene crystals: An application of fast-scan DSC, Polymer. 55 (2014) 3186-3194. doi:10.1016/j.polymer.2014.05.009.

[26] Y. Furushima, M. Nakada, M. Murakami, T. Yamane, A. Toda, C. Schick, Method for calculation of the lamellar thickness distribution of not reorganized linear polyethylene using fast scanning calorimetry in heating. Macromolecules. 48 (2015) 8831-8837. doi:10.1021/acs.macromol.5b02278.

[27] B. Wunderlich, G. Czornyj, A Study of Equilibrium Melting of Polyethylene, Macromolecules. 10 (1977) 906-913. doi:10.1021/ma60059a006.

[28] E. Zhuravlev E, C. Schick, Fast scanning power compensated differential scanning nano-calorimeter: 1. The device, Thermochim. Acta. 505 (2010) 14-21. doi:10.1016/j.tca.2010.03.019.

[29] R.S. Stein, M.B. Rhodes, Photographic light scattering by polyethylene films, J. Appl. Phys. 31 (1960) 1873-1884. doi:10.1063/1.1735468.

[30] S. Song, P. Wu, M. Ye, J. Feng, Y. Yang, Effect of small amount of ultra high molecular weight component on the crystallization behavior of bimodal high density polyethylene, Polymer. 49 (2008) 2964-2973. doi:10.1016/j.polymer.2008.04.050.

[31] Q. Bai, X. Wei, J. Yang, N. Zhang, T. Huang, Y. Wang, Z.W. Zhou, Dispersion and network formation of graphene platelets in polystyrene composites and the resultant conductive properties, Composites A. $96 \quad$ (2017) 89-98. doi:10.1016/j.compositesa.2017.02.020.

[32] PC Powder Diffraction Files, JCPDS-ICDD, 2003.

[33] D.G. Papageorgiou, I.A. Kinloch, R.J. Young, Graphene/elastomer nanocomposites, Carbon. 95 (2015) 460-484. doi:10.1016/j.carbon.2015.08.055. 
[34] H. Kim, C.W. Macosko, Morphology and Properties of Polyester/Exfoliated Graphite Nanocomposites, Macromolecules. $41 \quad$ (2008) 3317-3327. doi:10.1021/ma702385h.

[35] C. Vallés, A.M. Abdelkader, R.J. Young, I.A. Kinloc, The effect of flake diameter on the reinforcement of few-layer graphene-PMMA composites, Compos. Sci. Technol. 111 (2015) 17-22. doi:10.1016/j.compscitech.2015.01.005.

[36] X. Yan, Q. He, X. Zhang, H. Gu, H. Chen, Q. Wang, L. Sun, S. Wei, Z. Guo, Magnetic polystyrene nanocomposites reinforced with magnetite nanoparticles, Macromol. Mater. Eng. 299 (2014) 485-494. doi:10.1002/mame.201300208.

[37] R. Krishnamoorti, J. Ren, A.S. Silva, Shear response of layered silicate nanocomposites, Chem. Phys. 114 (2001) 4968. doi:10.1063/1.1345908.

[38] D.H. Xu, Z.G. Wang, Role of multi-wall carbon nanotube network in composites to crystallization of isotactic polypropylene matrix, Polymer. 49 (2008) 330-338. doi:10.1016/j.polymer.2007.11.041.

[39] R. Androsch, C. Schick, Crystal Nucleation of Polymers at High Supercooling of the Melt. In: F. Auriemma, G. Alfonso, C. de Rosa (eds), Polymer Crystallization I. Adv. Polym. Sci. 276 (2015). Springer, Cham. doi: 10.1007/12_2015_325.

[40] A.R. Adhikari, K. Lozano, M. Chipara, Non-isothermal crystallization kinetics of polyethylene/carbon nanofiber composites, J. Compos. Mater. 46 (2011) 823-832. doi:10.1177/0021998311410501.

[41] W. Zheng, X. Lu, S.C. Wong, Electrical and mechanical properties of expanded graphite- reinforced high- density polyethylene, J. Appl. Polym. Sci 91 (2004) 27812788. doi:10.1002/app.13460. 
[42] D.G. Papageorgiou, I.A. Kinloch, R.J. Young, Hybrid multifunctional graphene/glass-fibre polypropylene composites, Compos. Sci. Technol. 137 (2016) 44-51. doi:10.1016/j.compscitech.2016.10.018.

[43] B. Wunderlich, Crystal Melting, Macromolecular Physics; Academic: New York, 1980; Vol. 3, p 128.

[44] G. Amarasinghe, F. Chen, A. Genovese, R.A. Shanks, Thermal memory of polyethylenes analyzed by temperature modulated differential scanning calorimetry, J. Appl. Polym. Sci. 90 (2003) 681-692. doi:10.1002/app.12694.

[45] W.G. Harland, MM. Khadr, R. H. Peters, High-density polyethylene: thermal history and melting characteristics, Polymer. 13 (1972) 13-19. doi:10.1016/00323861(72)90029-8.

[46] S. Bensason, J. Minick, A. Moet, S. Chum, A. Hiltner, E.J. Baer, Classification of homogeneous ethylene-octene copolymers based on comonomer content, Polym. Sci. Part B: Polym. Phys. 34 (1996) 1301-1315. doi:10.1002/(SICI)10990488(199605)34:7<1301::AID-POLB12>3.0.CO;2-E.

[47] R. Androsch, B. Wunderlich, A Study of Annealing of Poly(ethylene-co-octene) by Temperature-Modulated and Standard Differential Scanning Calorimetry, Macromolecules. 32 (1999) 7238-7247. doi: 10.1021/ma9905223.

[48] V.B.F. Mathot, R.L. Scherrenberg, T.F.J. Pijpers, Metastability and order in linear, branched and copolymerized polyethylenes, Polymer. 39 (1998) 4541-4559. doi:10.1016/S0032-3861(97)10306-8.

[49] S. Tsubakihara, A. Nakamura, M. Yasuniwa, Melting and crystallization of ultrahigh molecular weight polyethylene with appearance of hexagonal phase I. melting processes of fibers under constrained state, Polymer J. 28 (1996) 489-495. doi:10.1295/polymj.28.489. 
[50] S. Yamazaki, M. Hikosaka, A. Toda A, I. Wataoka, Role of entanglement in nucleation and 'melt relaxation' of polyethylene, Polymer. 43 (2002) 6585-6593. doi:10.1016/S0032-3861(02)00592-X.

[51] B. Wunderlich, T. Arakawa, Polyethylene crystallized from the melt under elevated pressure, J. Polym. Sci. A 2 (1964) 3697-3704. doi: 10.1002/pol.1964.100020828.

[52] A.J. Crosby, J.Y. Lee, Polymer Nanocomposites: The "Nano" Effect on Mechanical Properties, Polym. Rev. $47 \quad$ (2007) 217-229. doi:10.1080/15583720701271278.

[53] D. Mileva, R. Androsch, E. Zhuravlev, C. Schick, Morphology of mesophase and crystals of polyamide 6 prepared in a fast scanning chip calorimeter, Polymer. 53 (2012) 3994-4001. doi:10.1016/j.polymer.2012.06.045.

[54] D. Mileva, I. Kolesov, R. Androsch, Morphology of cold-crystallized polyamide 6, Colloid. Polym. Sci. 290 (2012) 971-978. doi:10.1007/s00396-012-2657-3.

[55] Y.K. Kwon, A. Boller, M. Pyda, B. Wunderlich, Melting and heat capacity of gel-spun, ultra-high-molar-mass polyethylene fibers, Polymer. 41 (2000) 6237-6249. doi:10.1016/S0032-3861(99)00839-3.

[56] J.N. Hay, P.A. Fitzgerald, M. Wiles, Use of differential scanning calorimetry to study polymer crystallization kinetics, Polymer. 17 (1976) 1015-1018. doi:10.1016/0032-3861(76)90177-4.

[57] H.L. Friedman, Kinetics of thermal degradation of char-forming plastics from thermogravimetry-application to a phenolic resin, J. Polym. Sci. C 6 (1967) 183-195. doi:10.1002/polc.5070060121. 
[58] N. Bosq, N, Guigo, E. Zhuravlev, N. Sbirrazzuoli, Nonisothermal crystallization of polytetrafluoroethylene in a wide range of cooling rates, J. Phys. Chem. B 117 (2013) 3407-3434. doi: 10.1021/jp311196g. 


\section{Figure Captions}

Fig. 1. Polarized light microscopy of (a) HDPE/M5 and (b) HDPE/M25 nanocomposites

Fig. 2. X-ray diffraction patterns of neat HDPE, HDPE/M5 and HDPE/M25 nanocomposites. The peaks were indexed by use of PDF \#53-1859 (polyethylene).

Fig. 3. Rheological properties: (a) Storage and loss modulus, (b) mechanical loss factor, and (c) shear viscosity of neat HDPE, HDPE/M5 and HDPE/M25 nanocomposites

Fig. 4. Conventional DSC cooling curves of (a) neat HDPE and (b) HDPE/M5 nanocomposite at rates from 0.17 to $2.5 \mathrm{~K} / \mathrm{s}$

Fig. 5. FSC experiments for non-isothermal crystallization of HDPE/M5 nanocomposite at cooling rates from 1 to $10000 \mathrm{~K} / \mathrm{s}$

Fig. 6. (a) Crystallization peak temperature and (b) crystallization enthalpy for neat HDPE, HDPE/M5 and HDPE/M25 nanocomposites as a function of cooling rate using two types of scanning calorimeters- conventional DSC (center symbols) and FSC (open symbols)

Fig. 7. Melting peak temperatures of (a) neat HDPE and (b) HDPE/M5 nanocomposite at a heating rate of $0.33 \mathrm{~K} / \mathrm{s}$ after various cooling rates from 0.17 to $2.5 \mathrm{~K} / \mathrm{s}$

Fig. 8. Melting peak temperatures of (a) neat HDPE, (b) HDPE/M5 and (c) HDPE/M25 nanocomposites at a heating rate of $1000 \mathrm{~K} / \mathrm{s}$ after various cooling rates and (d) a curve deconvolution in the case of HDPE/M25 subsequent heated after cooling rate of $100 \mathrm{~K} / \mathrm{s}$

Fig. 9. (a) Melting peaks corresponding to the deconvolution process as shown in Fig. 8.d (cross symbols-Peak I, centerline symbols-Peak II, solid symbols-Peak III and 
open symbols-Peak IV) and (b) the total enthalpy for neat HDPE, HDPE/M5 and HDPE/M25 nanocomposites at a heating rate of $1000 \mathrm{~K} / \mathrm{s}$ as a function of the previous cooling rate in logarithmic scale

Fig. 10. Relative crystallinity of neat HDPE as a function of time for non-isothermal crystallization at cooling rates from 0.17 to $10000 \mathrm{~K} / \mathrm{s}$ collected by FSC (line) and conventional DSC (dotted line)

Fig. 11. Half time of non-isothermal crystallization of neat HDPE, HDPE/M5, HDPE/M15 and HDPE/M25 nanocomposites as a function of the cooling rate collected by conventional DSC (center filled symbols) and FSC (open symbols)

Fig. 12. Dependence of the apparent activation energy on (a) the relative crystallinity and (b) the temperature for neat HDPE, HDPE/M5 and HDPE/M25 nanocomposites determined by conventional DSC (filled symbols) and FSC (open symbols) 


\section{Table List}

Table 1: Melting temperature $\left(T_{m}\right)$, enthalpy of fusion $\left(\Delta H_{m}\right)$ and calculated crystallinity $\left(X_{c}\right)$ heating at $0.33 \mathrm{~K} / \mathrm{s}$ after various cooling rates for neat HDPE, HDPE/M5 and HDPE/M25 nanocomposites

\begin{tabular}{cccccccccc}
\hline Heating & \multicolumn{3}{c}{ HDPE } & \multicolumn{4}{c}{ HDPE/M5 } & \multicolumn{3}{c}{ HDPE/M25 } \\
\cline { 2 - 11 } rate & $\mathrm{T}_{\mathrm{m}}$ & $\Delta \mathrm{H}_{\mathrm{m}}$ & $\mathrm{X}_{\mathrm{c}}$ & $\mathrm{T}_{\mathrm{m}}$ & $\Delta \mathrm{H}_{\mathrm{m}}$ & $\mathrm{X}_{\mathrm{c}}$ & $\mathrm{T}_{\mathrm{m}}$ & $\Delta \mathrm{H}_{\mathrm{m}}$ & $\mathrm{X}_{\mathrm{c}}$ \\
$(0.33 \mathrm{~K} / \mathrm{s})$ & $(\mathrm{K})$ & $(\mathrm{J} / \mathrm{g})$ & $(\%)$ & $(\mathrm{K})$ & $(\mathrm{J} / \mathrm{g})$ & $(\%)$ & $(\mathrm{K})$ & $(\mathrm{J} / \mathrm{g})$ & $(\%)$ \\
\hline after 2.5 & 407.3 & 196.3 & 71 & 408.7 & 192.4 & 69 & 408.0 & 184.8 & 67 \\
after 1.67 & 407.7 & 197.0 & 71 & 408.9 & 194.4 & 70 & 408.4 & 186.8 & 67 \\
after 0.83 & 408.0 & 200.6 & 72 & 409.6 & 196.2 & 71 & 408.7 & 192.1 & 69 \\
after 0.33 & 408.6 & 207.0 & 7 & 410.3 & 203.8 & 73 & 409.3 & 197.8 & 71 \\
after 0.17 & 408.9 & 210.6 & 76 & 410.6 & 206.6 & 74 & 409.7 & 205.0 & 74 \\
\hline
\end{tabular}


Figures
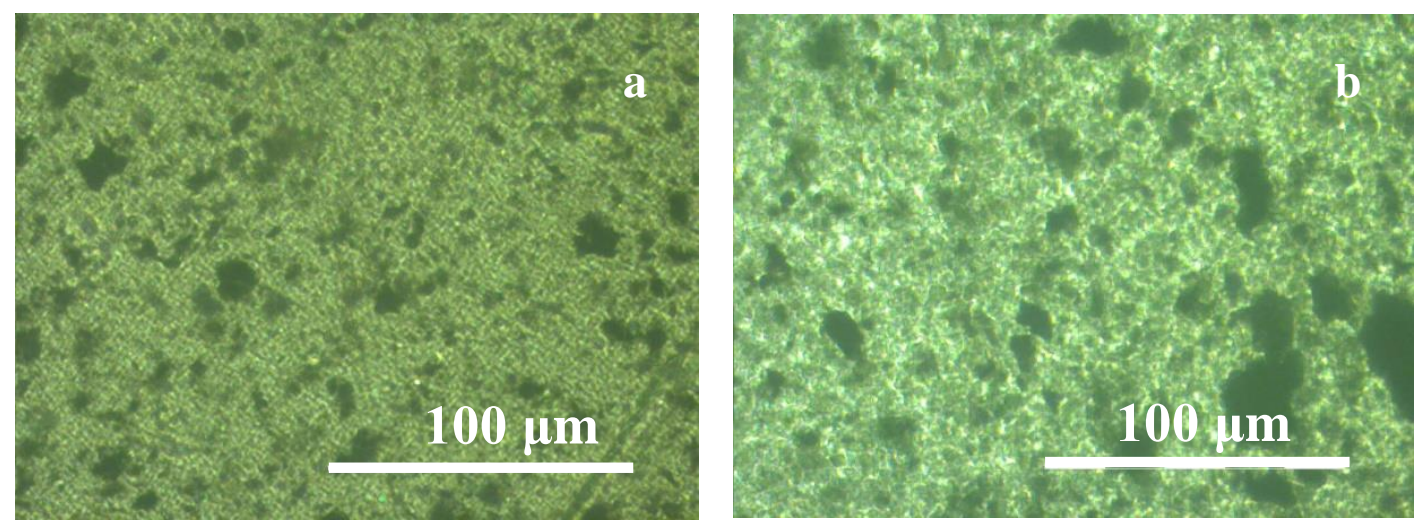

Fig. 1. Polarized light microscopy of (a) HDPE/M5 and (b) HDPE/M25 nanocomposites

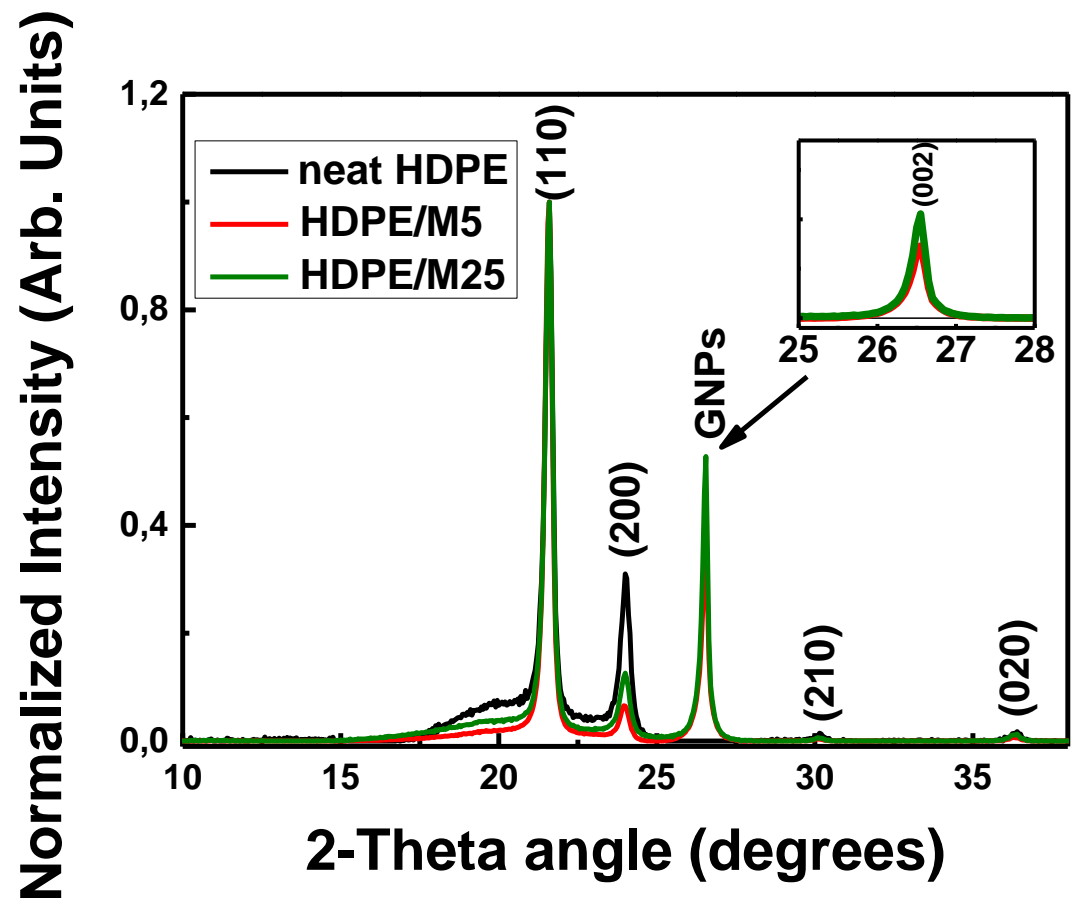

Fig. 2. X-ray diffraction patterns of neat HDPE, HDPE/M5 and HDPE/M25 nanocomposites. The peaks were indexed by use of PDF \#53-1859 (polyethylene) 

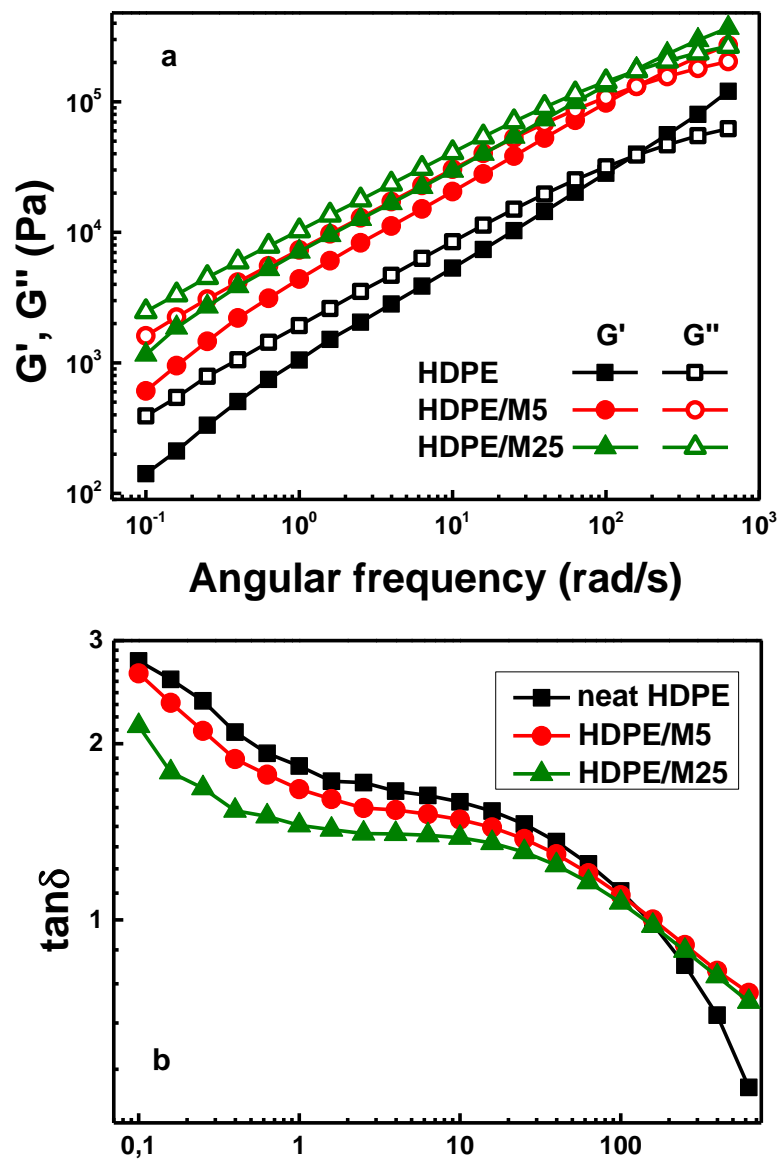

Angular frequency $(\mathrm{rad} / \mathrm{s})$



Fig.3. Rheological properties: a) Storage and loss modulus, b) mechanical loss factor, and c) shear viscosity of neat HDPE, HDPE/M5 and HDPE/M25 nanocomposites 

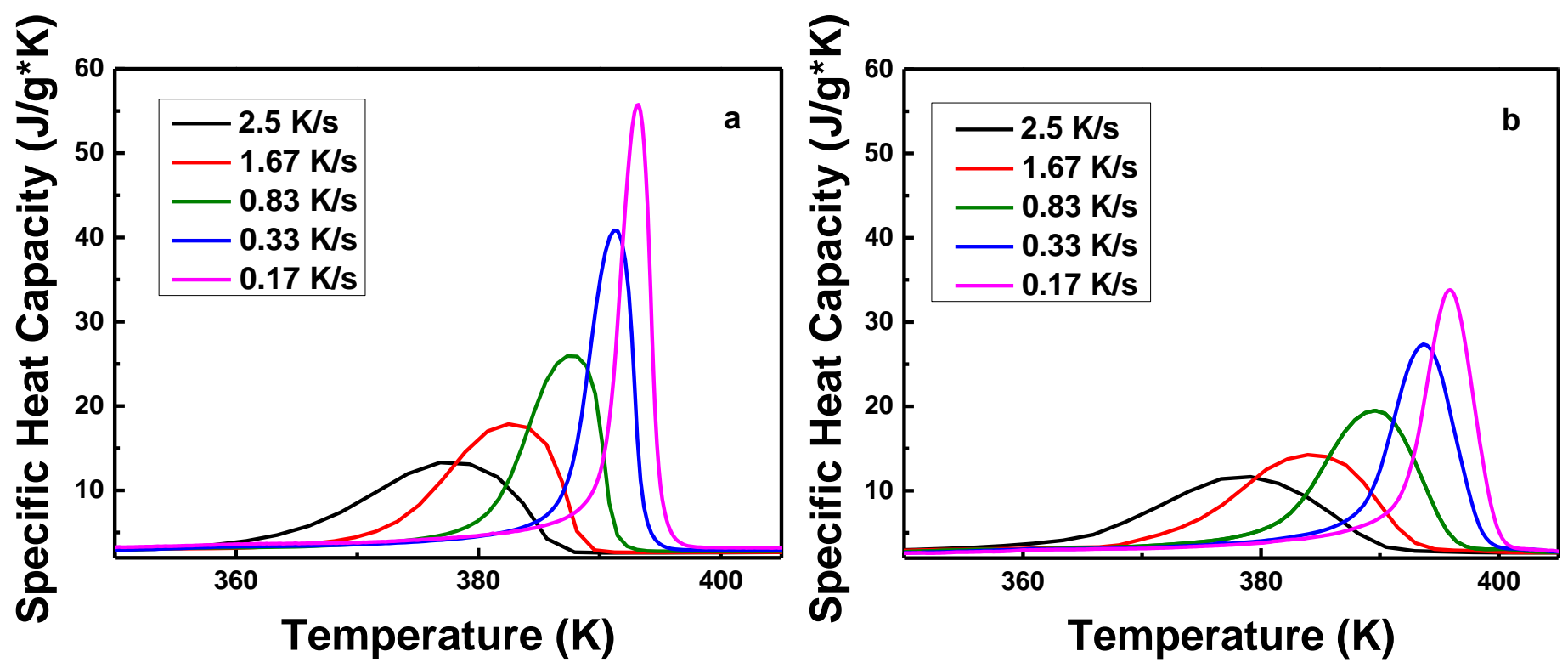

Fig. 4. Conventional DSC cooling curves of (a) neat HDPE and (b) HDPE/M5 nanocomposite at rates from 0.17 to $2.5 \mathrm{~K} / \mathrm{s}$

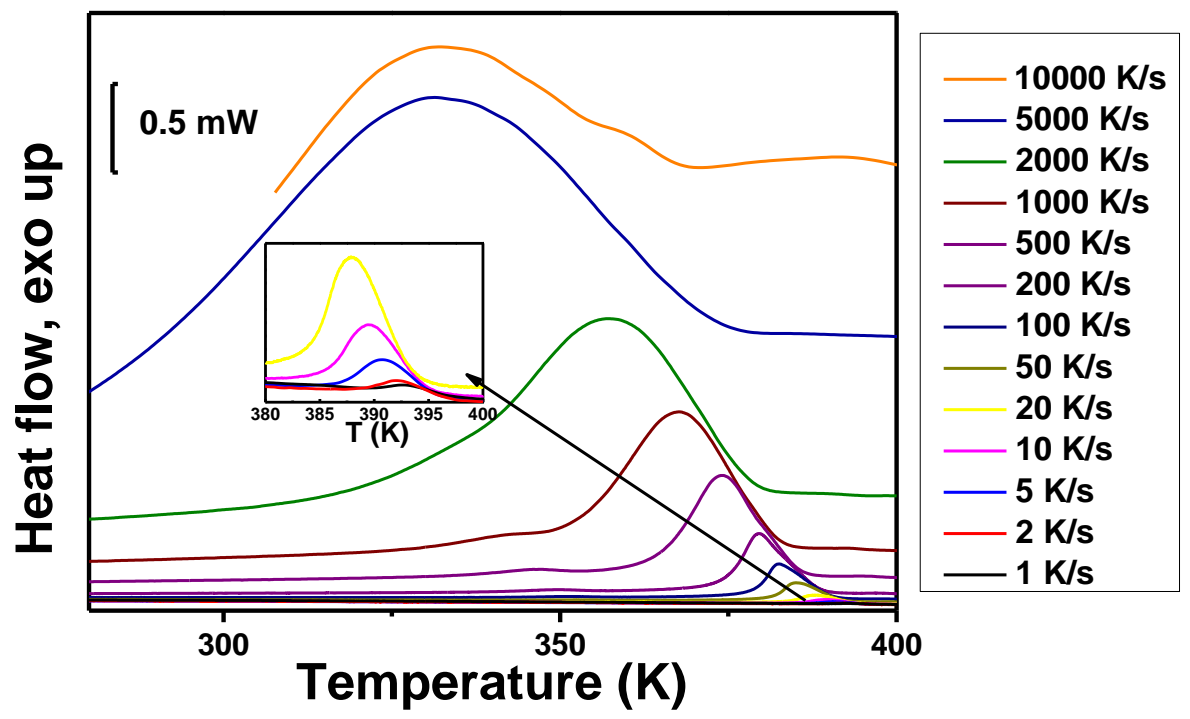

Fig. 5. FSC experiments for non-isothermal crystallization of HDPE/M5 nanocomposite at cooling rates from 1 to $10000 \mathrm{~K} / \mathrm{s}$ 

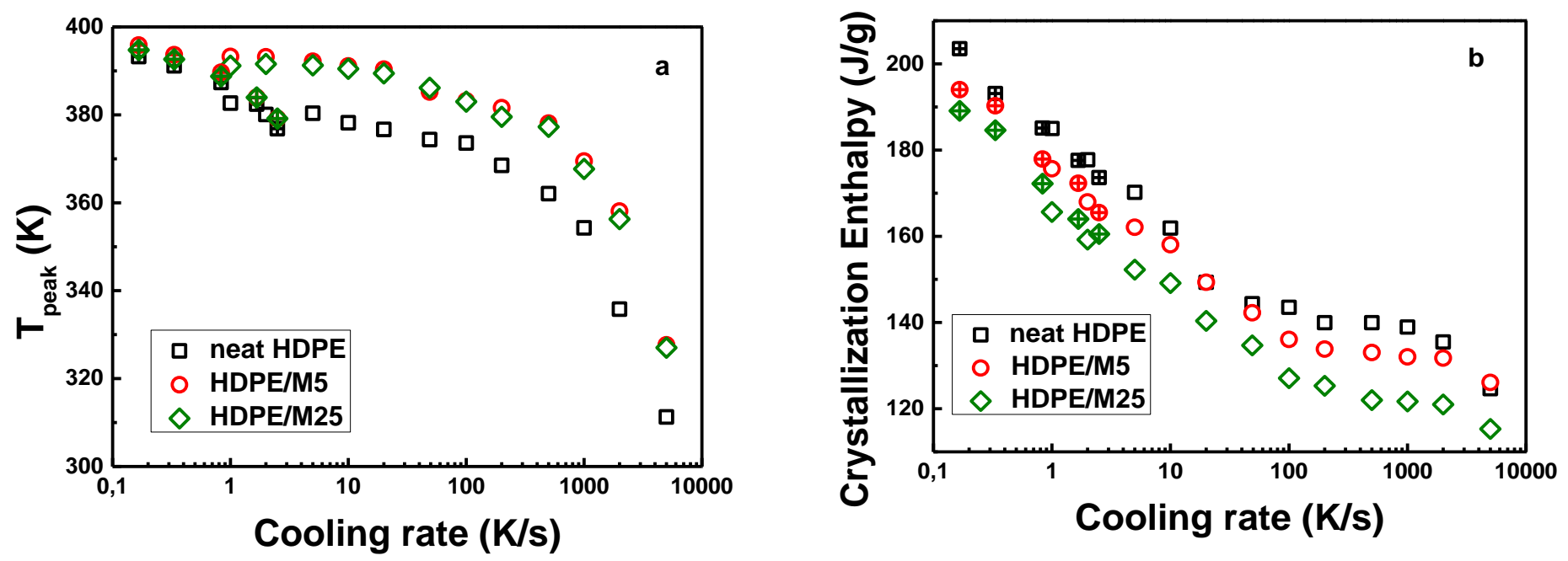

Fig. 6. (a) Crystallization peak temperature and (b) crystallization enthalpy for neat HDPE, HDPE/M5 and HDPE/M25 nanocomposites as a function of cooling rate using two types of scanning calorimeters- conventional DSC (center symbols) and FSC (open symbols)
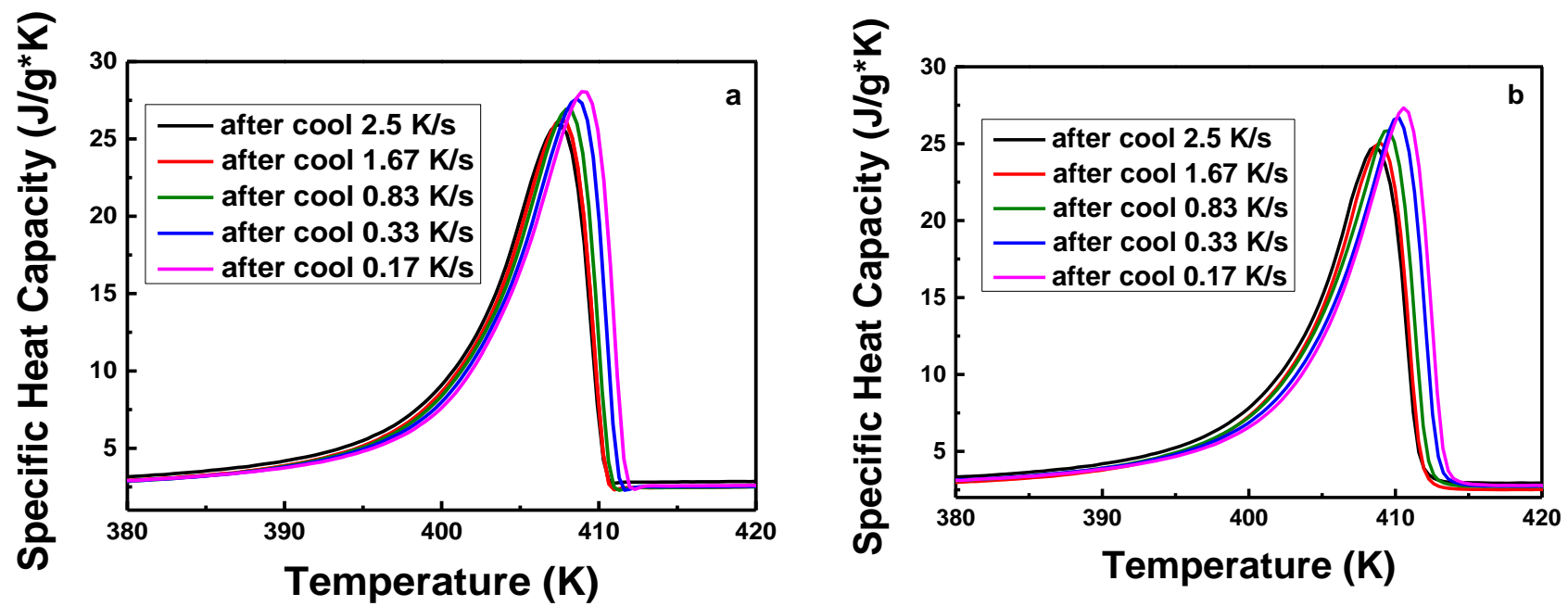

Fig. 7. Melting peak temperatures of (a) neat HDPE and (b) HDPE/M5 nanocomposite at a heating rate of $0.33 \mathrm{~K} / \mathrm{s}$ after various cooling rates from 0.17 to $2.5 \mathrm{~K} / \mathrm{s}$ 

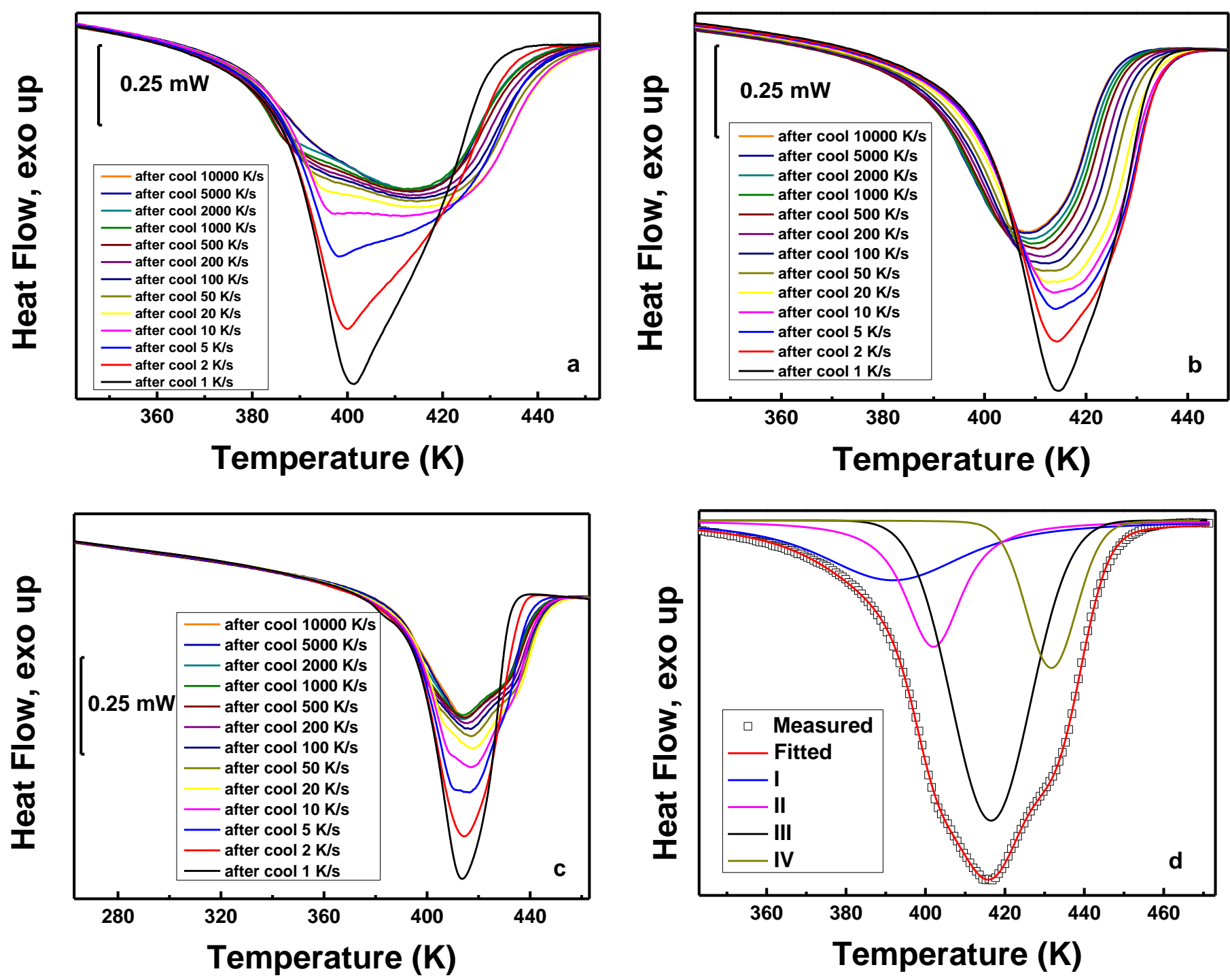

Fig. 8. Melting peak temperatures of (a) neat HDPE, (b) HDPE/M5 and (c) HDPE/M25 nanocomposites at a heating rate of $1000 \mathrm{~K} / \mathrm{s}$ after various cooling rates and (d) a curve deconvolution in the case of HDPE/M25 subsequent heated after cooling rate of $100 \mathrm{~K} / \mathrm{s}$ 

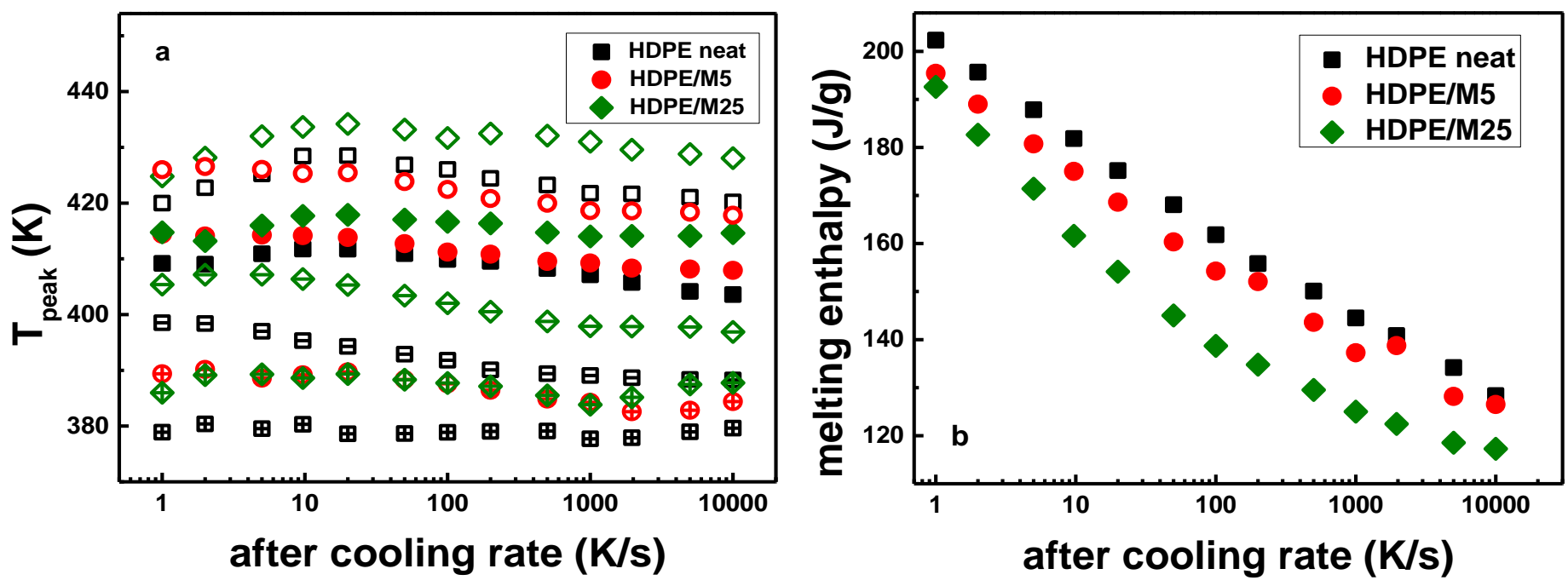

Fig. 9. (a) Melting peaks corresponding to the deconvolution process as shown in Fig.

8.d (cross symbols-Peak I, centerline symbols-Peak II, solid symbols-Peak III and open symbols-Peak IV) and (b) the total enthalpy for neat HDPE, HDPE/M5 and HDPE/M25 nanocomposites at a heating rate of $1000 \mathrm{~K} / \mathrm{s}$ as a function of the previous cooling rate in logarithmic scale

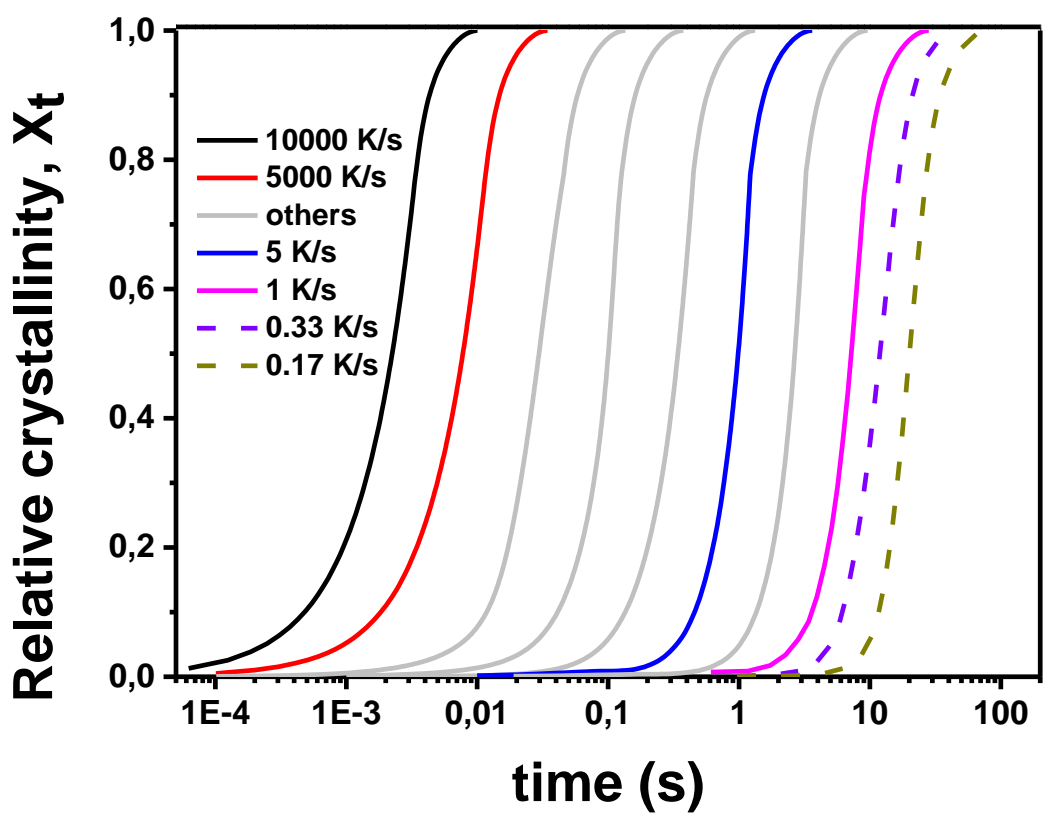


Fig.10. Relative crystallinity of neat HDPE as a function of time for non-isothermal crystallization at cooling rates from 0.17 to $10000 \mathrm{~K} / \mathrm{s}$ collected by FSC (line) and conventional DSC (dotted line)

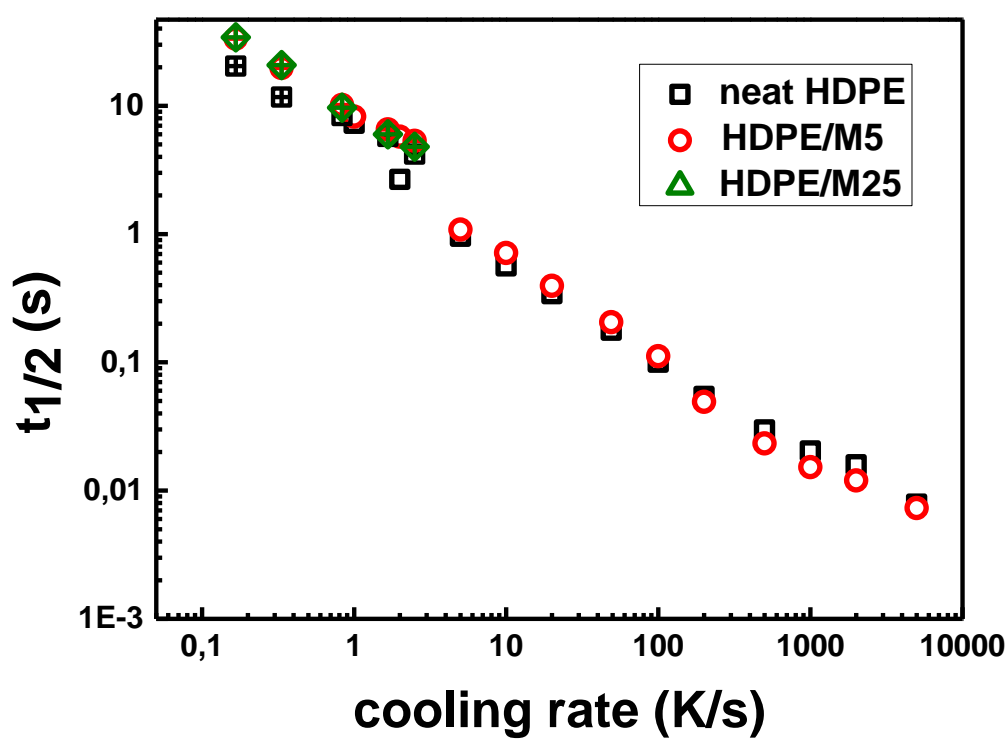

Fig. 11. Half time of non-isothermal crystallization $\left(t_{1 / 2}\right)$ of neat HDPE, HDPE/M5, HDPE/M15 and HDPE/M25 nanocomposites as a function of the cooling rate collected by conventional DSC (center filled symbols) and FSC (open symbols)
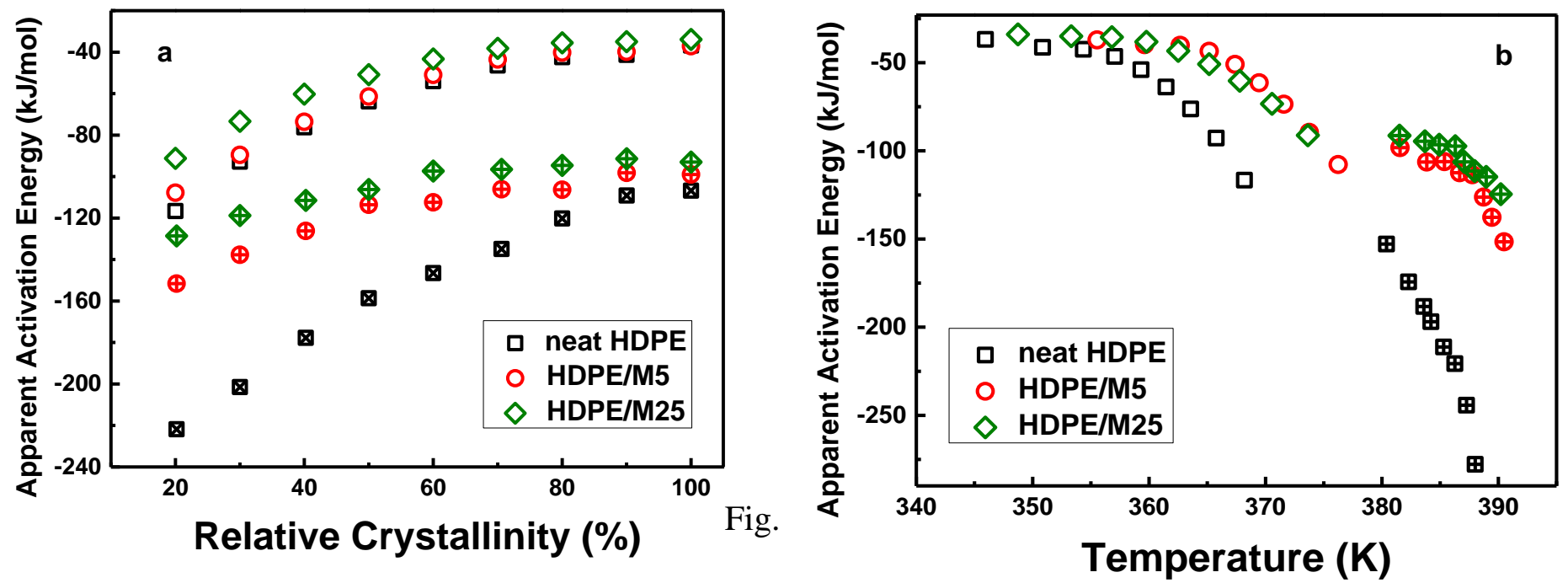

Figure 12. Dependence of the apparent activation energy on (a) the relative crystallinity and (b) the temperature for neat HDPE, HDPE/M5 and HDPE/M25 
nanocomposites determined by conventional DSC (filled symbols) and FSC (open symbols) 